\title{
Coverage of and barriers to routine child vaccination in Mukalla district, Hadramout governorate, Yemen
}

\author{
A.A. Ba'amer
}

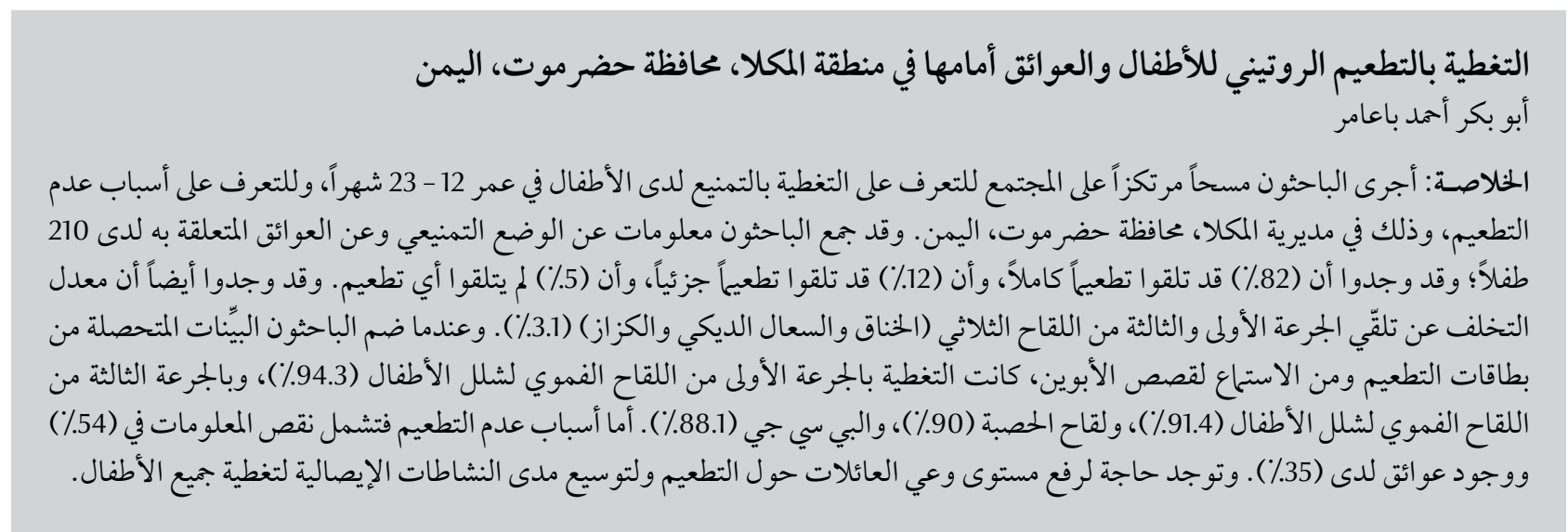

ABSTRACT To determine the vaccination coverage for children 12-23 months and to identify reasons for nonvaccination, we conducted a community-based survey in AI Mukalla district. Information about vaccination status and related barriers was collected for 210 children: $82 \%$ were fully vaccinated, $12 \%$ were partially vaccinated, and $5 \%$ were not vaccinated. Drop-out rate between DPT1 and DPT3 was 3.1\%. Combining the evidence of vaccine cards and parent's history, the coverage for OPV1 was 94.3\%, OPV3 91.4\%, measles 90\%, and BCG 88.1\%. Reasons for not vaccinating included lack of information (54\%) and existence of obstacles (35\%). There is a need to raise the awareness of families about vaccination and to expand continuous outreach sessions to cover all children.

Couverture de la vaccination des enfants et obstacles relatifs à celle-ci dans le district de Mukalla (gouvernorat d'Hadramout, Yémen)

RÉSUMÉ Afin d'évaluer la couverture vaccinale des enfants âgés de 12 à 23 mois et d'identifier les raisons de la non-vaccination, nous avons conduit une étude communautaire dans le district d'Al Mukalla. Les informations relatives au statut vaccinal et aux obstacles qui s'y rapportent ont été réunies pour 210 enfants : $82 \%$ d'entre eux étaient complètement vaccinés, $12 \%$ l'étaient en partie et $5 \%$ ne l'étaient pas. Le taux d'abandon entre la première dose du vaccin antidiphtérique-antitétanique-anticoquelucheux (DTC1) et la troisième dose de ce vaccin (DTC3) était de 3,1\%. D'après les fiches de vaccination et les antécédents familiaux, la couverture vaccinale était de $94,3 \%$ pour la première dose du vaccin antipoliomyélitique oral (VPO1), de 91,4\% pour la troisième dose (VPO3), de 90 \% pour le vaccin antirougeoleux et de 88,1\% pour le vaccin par le bacille de Calmette-Guérin (BCG). Les raisons de la non-vaccination étaient notamment le manque d'informations (54\%) et l'existence d'obstacles (35\%). Il est nécessaire d'améliorer la sensibilisation des familles sur la vaccination et d'étendre les séances périphériques permanentes afin d'offrir une couverture vaccinale à tous les enfants.

${ }^{7}$ Community and Family Medicine Department, Faculty ofMedicine and Health Sciences, Hadrmout University for Science and Technology, AlMukalla, Hadrmout, Yemen (correspondence to A.A.Ba'amer: aabaamer@maktoob.com).

Received: 27/06/07; accepted 19/11/07 


\section{Introduction}

Vaccines are one of the greatest achievements in medicine and public health, greatly reducing morbidity, mortality and health care costs. Despite spectacular recent progress, vaccination has not reached its full potential. At least 2 million people die every year from diseases preventable by vaccines recommended by the World Health Organization (WHO) [1]. Many developing countries have also seen major accomplishments in disease prevention because of the sustained use of vaccines. Yet, in order for vaccination programmes to be effective, high rates of coverage must be maintained. Even in countries like the United States of America, which have very successful programmes, coverage is often suboptimal in some geographic areas and sociodemographic groups [2].

In response to challenges in global immunization, WHO and UNICEF developed the Global Immunization Vision and Strategy, 2006-2015 (GIVS). One of the set goals of GIVS for any country is to reach at least $90 \%$ national vaccination coverage and at least $80 \%$ vaccination coverage in every district or equivalent administrative unit [3]. Local measurement of vaccination coverage is useful to identify pockets of low-coverage susceptible to outbreaks, and to determine special interventions needed to improve local coverage.

The Expanded Programme on Immunization (EPI) in Yemen is part of the Primary Health Care General Directorate in the Ministry of Public Health and Population. The goal of EPI is to prevent morbidity and mortality caused by diseases preventable through vaccination. The target groups are infants and women of child-bearing age. The recommended vaccination schedule includes vaccines against tuberculosis, poliomyelitis, measles, diphtheria, pertussis, hepatitis B, and diseases caused by Haemophilus influenzae. The goal of the EPI in Yemen is to achieve 90\% coverage for OPV3, DPT3, and measles and to achieve $80 \%$ coverage for hepatitis $\mathrm{B} 3$ before the age of 12 months by the end of 2005 .

The coverage of infants in 2005 in Yemen with BCG, OPV3, DPT3 and measles vaccines was $66 \%, 87 \%, 86 \%$, and $76 \%$ respectively [4]. Epidemics of measles and poliomyelitis have occurred in recent years. In 2005-2006 in Hadramout governorate, 7 cases of poliomyelitis occurred, 2 in Al Mukalla city district. The vaccination coverage of infants in Al Mukalla city district in 2004 was $66.5 \%, 108.0 \%, 95.9 \%$ and $96.4 \%$ for BCG, OPV3, HBV3 and measles respectively [5].

This study was carried out to determine the vaccination coverage for children 12-23 months in Al Mukalla city district, and to identify the reasons for non-vaccination.

\section{Methods}

Al Mukalla city district, the study area, includes Al Mukalla city and 10 surrounding villages. It is the capital of Hadramout governorate, which is in the south-eastern part of Yemen. The population of the district was estimated at 186896 in 2005 [6]. Twelve health facilities (4 mother and child health centres and 8 health units) in the district provide vaccination to children and women of childbearing age in addition to other preventive and curative health services.

The survey was conducted according to the standard method as a 30-cluster survey [7]. The sample size estimated according to this method was 210 ( 7 children in each cluster). For the calculation, desired precision was $10 \%$, confidence level was $95 \%$, design effect was 2 and expected vaccination coverage was 50\%-95\%.

Thirty clusters were randomly chosen from the 106 administrative divisions of the district, which were created for the purposes of the EPI national immunization days implemented in recent years, especially for Oral Polio Vaccine (OPV).

Door-to-door visits and face-to face interviews were conducted with parents or guardians of children 12-23 months old (at the time of the survey) until 7 eligible children were found for each cluster. During the household visits, we used 2 forms which were designed to obtain information from families on their children's vaccination status. Variables in Form 1 included cluster number, child's name, date of birth, sex, and type, dose and date of each vaccine. Form 2 included the reasons for any partial vaccination or non-vaccination of the child.

Data collection was done by a group of trained 3rd year medical students during the period 9 February-15 March 2006. The information about vaccination history was taken from the child's parent (or care-giver) if the vaccination card was unavailable (could not be found at the time of the interview, or lost). The interviewers were instructed and trained to get information in cases where there was no card by asking about the number of doses, route, and site of the particular vaccine. According to that information, they could judge the reliability of the vaccination history.

Epi-Info 2002 was used for data entry and analysis. To determine the vaccination status of the child, the analysis was done in steps. First we calculated the coverage with each vaccine according to the history, the information on the vaccination card and the vaccine validity. For the dose to be valid, the interval between doses had to be greater than a defined minimum and the dose had to be administered after a defined minimum age according to the standard criteria of the national EPI programme:

- Minimum age for DTP1, OPV1, HBV1, pentavalent 1: 6 weeks 
- Minimum age for measles and the third dose of HBV: 38 weeks

- Minimum interval between first and second doses of DTP or OPV or $\mathrm{HBV}$ or pentavalent vaccine: 4 weeks

- Minimum interval between second and third doses of HBV: 28 weeks

Finally, the numbers of partially and fully vaccinated children were determined according to the history, card evidence and vaccine validity.

A child was considered fully vaccinated if he/she had: 1 dose of BCG, 1 dose of measles, 3 doses of OPV (excluding OPV zero, which is given immediately after birth) and either 3 doses of DPT plus 3 doses of HBV or 3 doses of pentavalent vaccine.

A child who was not fully vaccinated but had had at least 1 dose of any vaccine was considered partially vaccinated.

The reasons for non-vaccination or partial vaccination were classified (according to the standard form) into 3 categories: lack of information, lack of motivation, and obstacle [7].

\section{Results}

Data were collected from 210 children aged 12-23 months. All families in the selected households were cooperative and willing to answer questions about the vaccination of their children and to show available vaccination cards to the interviewers. The mean age of the children was 18 (standard deviation 3.4) months. Cards had been retained by $140(66.7 \%)$. Combining the evidence of the cards and parents' history, vaccination coverage for OPV1, OPV3, measles 1 and BCG, was 94.3\%, 91.4\%, $90.0 \%$ and $88.1 \%$ respectively. Coverage for children who had a card was greater than overall coverage for each vaccine (Table 1).

Table 2 shows the number of valid doses (by card evidence). Applying all 3 dose validity criteria, there were only 114 valid doses out of 139 OPV1 doses

\begin{tabular}{|c|c|c|c|c|}
\hline \multirow[t]{2}{*}{ Vaccine } & \multicolumn{2}{|c|}{ Card $(n=140)$} & \multicolumn{2}{|c|}{ Card + history $(n=210)$} \\
\hline & No. & $\%$ & No. & $\%$ \\
\hline BCG & 130 & 92.9 & 185 & 88.1 \\
\hline DPT1/HBV1 & 131 & 93.6 & 190 & 90.5 \\
\hline DPT2/HBV2 & 130 & 92.9 & 186 & 88.6 \\
\hline DPT3 & 128 & 91.4 & 184 & 87.6 \\
\hline HBV3 & 126 & 90.0 & 182 & 86.7 \\
\hline OPV1 & 139 & 99.3 & 198 & 94.3 \\
\hline OPV2 & 138 & 98.6 & 194 & 92.4 \\
\hline OPV3 & 136 & 97.1 & 192 & 91.4 \\
\hline Measles1 & 134 & 95.7 & 189 & 90.0 \\
\hline Measles $2^{\text {a }}$ & 33 & 23.6 & 46 & 21.9 \\
\hline
\end{tabular}

${ }^{a}$ Given at age 18 months; 95 of the 210 children were aged under 18 months. received, only 100 valid doses out of 136 OPV3 doses received, and only 99 doses were valid out of 134 measles 1 doses received.

The number of fully vaccinated children was 173 (82.4\%), 120 according to vaccination cards and 53 from history evidence; 26 (12.4\%) children were partially vaccinated and 11 (5.2\%) were not vaccinated (Table 3 ).

The drop-out rate between DPT1 and DPT3 was 3.1\%, between DPT1 and measles 1 was $0.5 \%$.

Median age at the time when given BCG,DPT1,DPT2,DPT3 and measles was 11.8 weeks, 7.4 weeks, 12.8 weeks, 18.6 weeks and 39.6 weeks respectively.
The main reasons given by the parents of the 37 children for not vaccinating or partially vaccinating them were: unaware of need for vaccination, place or time of vaccination session unknown, and place too far (Table 4).

\section{Discussion}

The proportion of children with vaccination cards (vaccination card retention) in this survey (66.7\%) was lower than that (69.2\%) in the Yemen Demographic and Mother and Child Health Survey (YDMCHS) in 1997 [8], and higher than that in the UNICEF survey

\begin{tabular}{|c|c|c|c|c|c|}
\hline \multirow[t]{3}{*}{ Dose } & \multicolumn{4}{|c|}{ Valid dose criteria } & \multirow{3}{*}{$\begin{array}{c}\text { Total dose } \\
\text { by card } \\
(\boldsymbol{n}=140)\end{array}$} \\
\hline & \multirow{2}{*}{$\begin{array}{c}3 \\
\text { No. }\end{array}$} & \multirow{2}{*}{$\begin{array}{c}1+3 \\
\text { No. }\end{array}$} & \multicolumn{2}{|c|}{$1+2+3$} & \\
\hline & & & No. & $\%$ & \\
\hline BCG & 0 & 0 & 130 & 100 & 130 \\
\hline DPT1 & 0 & 0 & 109 & 83 & 131 \\
\hline DPT2 & 108 & 100 & 98 & 75 & 131 \\
\hline DPT3 & 98 & 96 & 96 & 74 & 130 \\
\hline HBV1 & 0 & 0 & 108 & 82 & 131 \\
\hline HBV2 & 107 & 96 & 95 & 73 & 130 \\
\hline HBV3 & 92 & 89 & 57 & 45 & 126 \\
\hline OPV1 & 0 & 0 & 114 & 82 & 139 \\
\hline OPV2 & 113 & 106 & 106 & 77 & 138 \\
\hline OPV3 & 104 & 100 & 100 & 74 & 136 \\
\hline Measles1 & 0 & 0 & 99 & 74 & 134 \\
\hline
\end{tabular}

Criteria: $1=$ satisfies requirement for minimum interval between doses; 2 = satisfies requirement of minimum age; 3 = satisfies requirement for valid previous dose. 


\begin{tabular}{|c|c|c|c|c|}
\hline \multirow[t]{2}{*}{ Status } & \multirow[t]{2}{*}{ By card } & \multirow[t]{2}{*}{ By history } & \multicolumn{2}{|c|}{ Total } \\
\hline & & & No. & $\%$ \\
\hline Fully vaccinated & $120^{\mathrm{a}}$ & 53 & 173 & 82.4 \\
\hline Partially vaccinated & 20 & 6 & 26 & 12.4 \\
\hline Not vaccinated & 0 & 11 & 11 & 5.2 \\
\hline Total & 140 & 70 & 210 & 100 \\
\hline
\end{tabular}

a 5 of 120 got the newly-introduced pentavalent vaccine.

(47\%) [9]. In the final YDMCHS report (1992), vaccination cards were seen by interviewers for only $40.3 \%$ of children aged $12-17$ months, and for only $28.0 \%$ of those aged 18-23 months, which is lower than in this study [10]. Vaccination coverage for children in the district for different vaccines ranged from $86.7 \%$ (HBV3) to $94.3 \%$ (OPV1) for all children in the sample, and from $90.0 \%$ to $99.3 \%$ with the same antigens for children who had vaccination cards. This coverage was lower than that in studies in Ethiopia [11] and in Saudi Arabia [12] for all antigens except for the measles vaccine: $75 \%$ for the Ethiopian study and 86\% for the Saudi Arabian study. However it was higher than the coverage found in YDMCHS 1992 and $1997[8,10]$, and in the UNICEF survey [9].
In this study, $82.4 \%$ of children were fully vaccinated. This is higher than the goal set recently by GIVS for coverage at district level. It was higher than in the Ethiopian study (75.5\%) [11], the Iraqi study (60\%) [13], YDMCHS 1992 [10] (45\%) and 1997 [8] (28\%), and the UNICEF survey (28\%) [9], but lower than in a 1991 Saudi Arabian study (91.9\%) [12].

The proportion of non-vaccinated children in this study was $5.2 \%$ compared with $37 \%, 12 \%$, and $8 \%$ according to the YDMCHS 1997, YDMCHS 1992, and the Saudi Arabian study respectively $[8,10,12]$. These differences are due to the improvement of the Yemeni EPI services in recent years. Another reason for this difference is the area covered by our survey (urban) versus the areas (urban and rural) covered by the national YDMCH survey, which found that urban children were much more likely to be vaccinated than rural children ( $56 \%$ versus $20 \%$ in 1997 , and $72 \%$ versus $39 \%$ in 1992$)[8,10]$.

The coverage with valid doses of the multidose vaccines (OPV, DPT, and $\mathrm{HBV}$ ) was in the range $82 \%-83 \%$ for the first dose. For the second dose it ranged from $73 \%$ to $77 \%$, and for the valid third dose it was $74 \%$ for OPV3 and DPT 3 but only $45 \%$ for HBV3. The reasons for invalid doses were giving the vaccine too early and/or shorter time interval between the subsequent doses than the recommended, and/or an invalid previous dose.

The reasons for not vaccinating the child or not completing the course of vaccination were mostly due to lack of information. This is similar to the results of an Iraqi study [13]. For children in the YDMCHS 1992, obstacles (mainly "place of vaccination is too far") were the main reasons children did not complete vaccination or were not vaccinated, however the results of the same survey showed that, for urban children, the reason cited most often by parents/caretakers was the lack of information [10].

\begin{tabular}{|c|c|c|c|c|c|c|}
\hline \multirow[t]{2}{*}{ Cause } & \multicolumn{2}{|c|}{$\begin{array}{l}\text { No vaccination } \\
\qquad(n=11)\end{array}$} & \multicolumn{2}{|c|}{$\begin{array}{l}\text { Partial vaccination } \\
\qquad(n=26)\end{array}$} & \multicolumn{2}{|c|}{ Total $(n=37)$} \\
\hline & No. & $\%$ & No. & $\%$ & No. & $\%$ \\
\hline \multicolumn{7}{|l|}{ Lack of information } \\
\hline Unaware of need & 3 & 27.3 & 4 & 15.4 & 7 & 18.9 \\
\hline Place and/or time of vaccination unknown & 1 & 9.1 & 5 & 19.2 & 6 & 16.2 \\
\hline Other & $1^{\mathrm{a}}$ & 9.1 & 6 & 23.1 & 7 & 18.9 \\
\hline Total & 5 & 45.5 & 15 & 57.7 & 20 & 54.1 \\
\hline \multicolumn{7}{|l|}{ Lack of motivation } \\
\hline Postpone until another time & 0 & 0 & 4 & 15.4 & 4 & 10.8 \\
\hline \multicolumn{7}{|l|}{ Obstacle } \\
\hline Place of vaccination too far & 4 & 36.4 & 1 & 3.8 & 5 & 13.5 \\
\hline Vaccine not available & 0 & 0 & 4 & 15.4 & 4 & 10.8 \\
\hline Other & $2^{b}$ & 18.2 & $2^{c}$ & 7.7 & 4 & 10.8 \\
\hline Total & 6 & 54.5 & 7 & 26.9 & 13 & 35.1 \\
\hline
\end{tabular}

${ }^{a}$ Fear of side effect.

${ }^{b}$ Mother too busy

${ }^{c}$ Child ill. 
There was a delay in receiving the BCG vaccine (median age 11.8 weeks), this was due to interrupted supply of this vaccine. This was confirmed by the EPI programme report for the same period [5].

Only 8 children received pentavalent vaccine as it was introduced to the vaccination schedule in April 2005.

The high coverage of OPV and measles compared to the national figures was due to the effect of vaccination campaigns for these implemented during the years previous to this cluster survey.

Our results should be interpreted with caution due to the following study limitations. The sample frame used to select clusters was administrative divisions (detailed census data could not be obtained for the district), the determination of the child's age when there was no card depended on the caretaker's recall, and the assumption of correct recording in the vaccination card by vaccinators may not be true for all children.

The coverage as estimated by this survey showed a high access rate to vaccination services in most cluster areas; however the greatest number of unvaccinated children was from areas relatively far from the vaccination centres (at the periphery of the district).
In conclusion, the survey shows high coverage of children with routine vaccination, low drop-out rate, and some receiving invalid doses.

The results of the survey demonstrate the need to improve the quality of the vaccination programme, this improvement can be achieved through acceleration of the health education programme to guarantee that all families know all the necessary facts about immunization, ensuring continuous supply of vaccines, and starting outreach vaccination sessions to cover areas far from the vaccination centres.

\section{References}

1. Vaccine-preventable diseases. Geneva, World Health Organization, (http//www.who.int/media centre/events/2006/ g8summit/vaccines/en/index.html, accessed 22 March 2007).

2. Rosenthal J et al. Immunization coverage levels among 19- to 35 -month-old children in 4 diverse, medically underserved areas of the United States. Pediatrics, 2004, 113(4):e296-302.

3. Global immunization vision and strategy (GIVS). Geneva, World Health Organization, 2009 (http://www.who.int/immunization/givs/en/index.html, accessed on 28 June 2009).

4. Country profiles: Yemen. Cairo, World Health Organization Regional Office for the Eastern Mediterranean, 2007 (http:// www.emro.who.int/emrinfo/index.asp?Ctry=yem, accessed 20 May 2007).

5. [Annual reports of EPI program 2004, 2005]. Hadrmout Governorate, Office of Ministry of Public Health and Population, 2005 [in Arabic].

6. [Results of 2004 population census]. Hadramout, Office of Central Statistical Organization (CSO), 2005 [in Arabic].

7. Immunization coverage cluster survey: reference manual. Geneva, World Health Organization, 2004 (WHO/IVB/04.23).
8. Pan Arab project for child development, Cairo, Egypt, health surveys: YDMCHS Final Report 1997, Sana'a. Sana'a, Yemen, Central Statistical Organization and Calverton, Maryland, Macro International Inc., 1977:122-7.

9. Hashim M. Vaccination coverage survey and EPI evaluation for the UNICEF Community Development Project Area, July 2-21. Sana'a, Yemen UNICEF, 2004.

10. Pan Arab project for child development, Cairo, Egypt, health surveys: YDMCHS final report 1991-92, Sana'a. Sana'a, Yemen, Central Statistical Organization and Calverton, Maryland, Macro International Inc., 1994:105-11.

11. Kidane T, Tekie M. Factors influencing child immunization coverage in a rural district of Ethiopia, 2000. Ethiopian journal of health development, 2003, 17(2):105-10.

12. Al-Shehri SN, Al-Shammari SA. Immunization coverage survey in eight regions of Saudi Arabia. Annals of tropical pediatrics, 1991, 11(2):181-7.

13. Al-Sheikh OG, Al-Samarrai JI, Al-Dujaily AA. Immunization coverage among children born between 1989 and 1994 in Saladdin Governorate, Iraq. Eastern Mediterranean health journal, 1999, 5(5):933-40. 